\title{
La generación de Taller, la presencia de Federico García Lorca en la revista y en Octavio Paz
}

\author{
Alicia Correa PÉrez
}

\section{GENERACIONES}

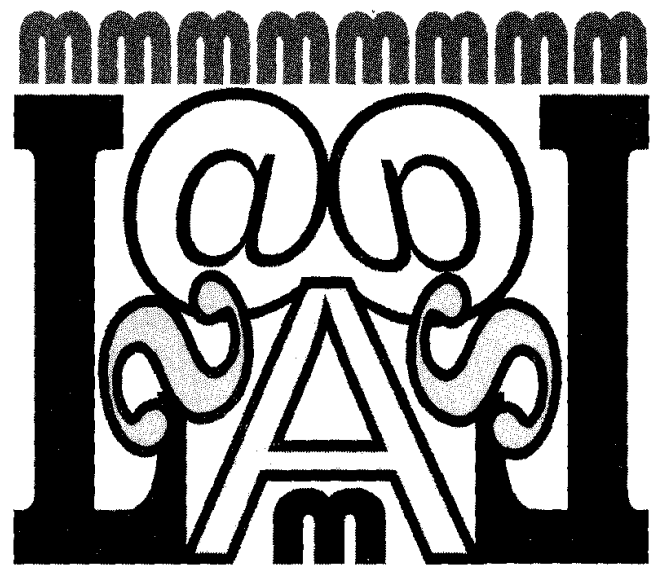

$\mathbf{L}$ as generaciones son ritmos históricos, acumulan y reciben, heredan y dejan cos se caracterizan por bruscas revoluciones y reacciones; éstas últimas pueden ser violentas o pacíficas, pero siempre existen. Inevitablemente, sus agentes son los seres humanos que, no aislados, sino en grupo, unidos por el tiempo y el acaso, por la libertad de la razón y por un sentido de conciencia unánime, toman una decisión casi siempre benéfica para el desarrollo de la cultura.

Ortega y Gasset afirma que el problema de toda generación consiste en saber qué es lo que hereda y qué es lo que agrega. La herencia, en el caso de la generación que la recibe, supone, sin duda, el esfuerzo de incorporar lo anterior. Los jóvenes heredan de los predecesores no una obra, sino instrumentos y situaciones para crear la suya propia y, posteriormente dejan fluir su propia espontaneidad. Siempre, para la nuevas generaciones, y en todos los tiempos, hay de frente un amplio territorio que explorar, listo para dejar huella.

La generación de Taller, que se inicia con la revista del mismo nombre en diciembre de 1938, a diferencia de otras, no fue rebelde a sus mayores (tanto a la generación de los Contemporáneos, como a la poesía europea de principios de siglo) en lo que respecta a los gustos y preferencias estéticas y al compromiso literario, pero sí lo fue en cuanto a su postura frente a la poesía y al compromiso social. Para los de Taller, lo importante no era repetir la experiencia de sus predecesores, sino construir un orden con todas las experiencias del hombre y continuar abriendo rutas para crear su propia obra. De esta manera, una de las tareas de la nueva generación fue profundizar la renovación iniciada por los anteriores. En el "manifiesto" de la generación de Taller, que se encuenta con- 
centrado en el artículo "Razón de ser", publicado en el número dos de la revista Taller, en abril de 1939; su autor, Octavio Paz, expresa que "la herencia no es un sillón, sino un hacha para abrirse paso. Los mejores de los que nos anteceden también usan de esta delicada y resistente hacha: el sentido de su obra actual, en cierto modo, es más 'contemporáneo' de nosotros que su obra juvenil".

Heredaron la "modernidad" de los simbolistas, la inspiración y la fuerza poética de la poesía surrealista, la tradición y la vanguardia de los poetas españoles de la generación del 27, el sentido totalizante de la poesía de los Contemporáneos, pero modificaron esa tradición con nuevas lecturas (Nietzche y Trotski, Spengler y Berdieaev, Freud y Heidegger, Valéry, Ortega y Gasset, André Gide, Malraux, Ezra Pound). En esa época en que triunfaba el nacionalismo y el realismo socialista, proclamaron la libertad del arte, no hicieron poesía política y se opusieron al arte de propaganda para afirmar la libertad de la literatura; y se inclinaron - ya que tenían una conciencia más viva del tiempo, más honda y total, y sentían la crisis general y moral de la civilización- más por el tema: poesía e historia, que poesía y filosofía, sin abandonar a esta última.

El grupo central de la generación de Taller tenía ya anteriormente publicaciones personales y participaciones en otras revistas literarias, entre ellas $B a$ randal (iniciada por Octavio Paz a los 17 años, siete números, de agosto de 1931 a marzo de 1932) y Cuadernos del Valle de México (también iniciada por Octavio Paz, dos números, en septiembre de 1933 y enero de 1934). El antecedente más inmediato de Taller fue Taller poético, fundada por Rafael Solana, "El más activo y generoso de esta generación", según palabras de Octavio Paz. Se caracteriza por una excelente tipografía, y destacadas colaboraciones impresas manualmente por el poeta Miguel N. Lira, corresponsable de la misma. En ocasiones, el propio ministro de Relaciones Exteriores, Genaro Estrada, manejaba la imprenta y regalaba el papel para alguna lujosa edición, según comenta el propio Rafael Solana. Justamente Genaro Estrada jugará un papel muy importante en la presencia de García Lorca en la revista Taller.

Rafael Solana, responsable y fundador de Taller poético, con el propósito de acercarse a todos los grupos prexistentes y a los que fueran surgiendo, invitó a colaborar en su revista a Efraín Huerta, compañero de la Escuela Nacional Preparatoria; a Octavio Paz, condiscípulo de la escuela secundaria; al recién llegado de provincia Alberto Quintero Álvarez y a otros poetas como Efrén Hernández, Neftalí Beltrán, Enrique Gabriel Guerrero, Enrique Asúnsolo, Vicente Magdaleno, Octavio G. Barreda y, por supuesto, a los poetas de Contemporáneos. En ese momento, Octavio Paz había fracasado en su intento por formar un grupo, en las revistas Barandal y Cuadernos del Valle de México; por 
ello, sugiere a Rafael Solana convertir Taller poético en una revista que contuviese también los otros géneros y constituyera un grupo más sólido, generacional. De esta manera nace Taller en diciembre de 1938, publica doce números; el último de ellos sale a la luz en febrero de 1941.

Taller es el mejor intento y fructífero logro de los más destacados escritores de una nueva época. Éstos fueron: Octavio Paz, Rafael Solana, Efraín Huerta, Alberto Quintero Álvarez - los cuatro responsables de la revista-, Neftalí Beltrán, Manuel N. Lira, Efrén Hernández, José Revueltas, Enrique Gabriel Guerrero, Vicente Magdaleno, Rafael Vega Albela, Octavio Novaro, Carmen Toscano, Mauricio Gómez Mayorga, Manuel Lerín; nacidos, en su mayoría, entre 1912 y 1916. Reúne a los exiliados trasterrados, entre ellos, los que publicaban la revista Hora de España: Antonio Sánchez Barbudo, José Bergamín, Juan Gil-Albert, Lorenzo Varela, Ramón Gaya, José Herrera Petere y, esporádicamente, León Felipe y Manuel Altolaguirre. No hubo un director, pero sí cuatro responsables en los cuatro primeros números. A partir del quinto número, octubre de 1939, Taller acoge en sus páginas a los exiliados españoles y, por ausencia de Rafael Solana quien viajó a Europa, Octavio Paz se convierte en el director de la revista.

La revista Taller fue el órgano de sus mensajes, de su pensamiento nuevo y actual, identificado con todas las preocupaciones y las necesidades de la época. Este grupo, como afirmó Alberto Quintero Álvarez, fue una generación unida, un grupo uniforme, porque el nexo espiritual existió en la necesidad de crear. Se cultivaron, produjeron y publicaron, lucharon por la poesía, como la generación anterior y con su ejemplo.

\section{CUERPO POÉTICO DE TALLER}

El cuerpo poético de una revista está íntimamente ligado a las ideas poéticas del grupo que la produce, al objetivo, al ideal. Un cuerpo poético integra nombres, circunstancias, historia, y marca también su trascendencia a través del tiempo. Taller responde a las necesidades de la revista en lo que se refiere a esa actividad vital, a ese acto colectivo, al nombre mismo de la revista, al quehacer poético. Pero también demuestra un carácter histórico-literario que como generación pretendía una práctica y una poética ordenada, sistematizada y válida para la experiencia del lenguaje.

De esta manera, el cuerpo poético de Taller está formado por los siguientes rubros y poetas:

1. Las traducciones de Arthur Rimbaud, Friedrich Horlderlin, T. S. Eliot, Giacomo Leopardi, Charles Baudelaire, Stephan Spender, Paul Verlaine. 
2. Los clásicos del siglo xvII en lengua española: Francisco de Quevedo, Sor Juana Inés de la Cruz, Juan Ruiz de Alarcón, Luis Carrillo de Sotomayor, Francisco de Quevedo, Luis Martín de la Plaza, El conde Bernardino de Rebolledo, el conde de Villamediana - Juan de Tasis- y Doña Cristobalina (de Alvarado).

3. Los españoles: Federico García Lorca, Antonio Machado, Juan Ramón Jiménez, Miguel de Unamuno, y los exiliados: Rafael Alberti, Luis Cernuda, León Felipe, Juan Rejano, Emilio Prados, Francisco Giner de los Ríos, Juan Gil Albert, José Bergamín, Antonio Sánchez Barbudo, Adolfo Sánchez Vázquez, Lorenzo Varela.

4. Los hispanoamericanos. Pablo Neruda, Sara de Ibáñez y Luis Cardosa y Aragón.

5. Los mexicanos. Entre los ateneístas a Alfonso Reyes; de la generación de los contemporáneos: Carlos Pellicer, Xavier Villaurrutia, Enrique González Rojo, Bernardo Ortiz de Montellanos, Jorge Cuesta. Y los redactores de la revista: que cité anteriormente: Alberto Quintero Álvarez, Efraín Huerta, Octavio Paz, Rafael Solana, Rafael Vega Albela, Neftalí Beltrán, Enrique Gabriel Guerrero, Efrén Henández, Octavio G. Barreda. Cabe señalar la presencia de la poesía de Adolfo Sánchez Vázquez y la narrativa de José Revueltas.

Las traducciones de Taller revelan el gusto por una poesía "espiritual", profunda, del interior del ser humano. Sus autores, Rimbaud, Baudelaire, Novalis, Eliot eran un modelo estético, "un ejercicio espiritual" como decía Octavio Paz; a todos les interesaban estas obras como experiencia. Por esas traducciones entendemos que este grupo se encuentra afectado por el temperamento y la estética llena de rebeldía y exaltación del romanticismo y de los grandes poetas simbolistas del siglo xix, por los textos poéticos relevantes de principios de este siglo como "Tierra baldía", así como de la fuerza poética del surrealismo.

La poesía de los españoles, no sólo del exilio sino también de las generaciones anteriores, como la de Juan Ramón Jiménez y Antonio Machado, y la de Federico García Lorca y Rafael Alberti, indican la identificación de esta generación tanto con su poesía como con la lucha política española.

Para Paz, como director de la revista, Taller debía ser la receptora y emisora de la experiencia poética del exilio español; de esta manera, la poesía se subordinaba al destino cultural de un grupo social disperso geográficamente. 
Así Taller negaba la nacionalidad de los quehaceres poéticos y favorecía el encuentro con los españoles para ser congruentes con su ideología poética y política. Solana no pensaba de esa manera; tanto que a los poetas exiliados que se insertaron en la redacción de Taller los llamó "la influenza española".

\section{EL QUEHACER POÉTICO}

Como la mayoría de los colaboradores se iniciaron en la poesía, su preocupación mayor consistió no tanto en definirla como en realizarla. Pero expresaron que ella era inquietud de retorno, de introversión, esa sed amorosa por despejar las insinceridades del tiempo y establecer el contacto con los verdaderos orígenes: "era una tentativa para recobrar al hombre adánico", según palabras de Octavio Paz.

Todos los poetas que formaron el grupo de Taller introdujeron el surrealismo a su poesía, en el atrevimiento de la imagen y en la renovada voluntad creadora. La preocupación simbolista de la sugerencia en la imagen es también una constante de su producción poética. Temáticamente tuvieron, como ya se expresó, el deseo de recobrar, al contacto con los verdaderos orígenes, la tentativa de "volver al hombre adánico, anterior a la escisión y la desgarradura”, porque Adán fue el único "claro cantor" y su poesía fue el nombramiento simple de la belleza surgida del asombro del perfecto contemplador. Su propósito fue también modificar al hombre y a la sociedad, aunque sentían sus limitaciones.

Debemos recordar aquí que la poesía no fue el vehículo general que utilizó el grupo para expresar su ideología; el ensayo filosófico, el sociológico, la crítica, la autocrítica, el análisis, la narrativa también lo fueron.

\section{¿CUÁL ES LA PRESENCIA DE FEDERICO GARCÍA LORCA EN TALLER Y POR QUÉ?}

La presencia de García Lorca no llegó por azar a Taller. Como ya se expresó renglones arriba, esta generación poética muestra influencias y afinidades con los surrealistas; pero de ellos, como expresa Octavio Paz, no les interesaba el lenguaje del surrealismo, ni sus teorías sobre la escritura automática sino:

"nos seducía su afirmación intransigente de ciertos valores que considerábamos - y considero- preciosos entre todos: la imaginación, el amor y la libertad, únicas fuerzas capaces de consagrar al mundo y volverlo de veras 'otro'. Nada más natural que en este estado de espíritu volviésemos los ojos hacia ciertos poetas de nuestra lengua tocados por el surrealismo y que encarnaban con brillo sin igual estas tendencias: Cernuda, 
García Lorca, Aleixandre, Neruda, Prados, Altolaguirre, Alberti. Creo que ellos influyeron un poco más profundamente en nuestra generación que los contemporáneos."

No cabe duda que en el momento de la publicación de la revista, los responsables de ella habían conocido, analizado, comentado, criticado la poesía de los escritores del 27, quienes ya habían asimilado ciertos valores del surrealismo y actitudes poéticas que también seducían a los de Taller. Entre ellos: la afirmación intransigente de la imaginación, (lo maravilloso), el amor, la palabra y la libertad como sinónimos ardientes, como fuerzas capaces de realizar al hombre en plenitud y en el otro, "el otro todos que nosotros somos". "Concebíamos a la poesía como un salto mortal, experiencia capaz de sacudir los cimientos del ser y llevarlo a la otra orilla, ahí donde pactan los contrarios de que estamos hechos."

De esta manera, la tarea del grupo de Taller estaba reclamando la atención de literatos y de críticos al publicar la poesía de autores tan célebres como García Lorca, Juan Ramón Jiménez, Rafael Alberti, Carlos Pellicer, Villaurrutia.

Necesitaban la poesía de García Lorca en su primer número, pero no cualquier poema, sino aquellos que se identificaran con la postura e ideología poética del grupo. Rafael Solana había enviado invitación a García Lorca para que participara en Taller poético, en mayo de 1936; Lorca muere en diciembre de 1936. El propio Solana aclara que García Lorca y José Moreno Villa fueron invitados, mientras el grupo de españoles trasterrados que Octavio Paz aceptó a partir del quinto número no lo fueron y no le parecían de la talla de Taller:

"Pienso que no fue un acierto el de Octavio Paz al admitir, no como invitados, como se hizo con García Lorca y Moreno Villa que habían estado desde el principio, sino a quienes sólo pasaron por la revista como por un cuarto de hotel, provisionalmente y mientras encontraban otra cosa."

Estas palabras muestran no sólo la preocupación de la calidad de los participantes de la revista, que Solana refleja, sino también la invitación especial a García Lorca.

Precisamente fue el propio Genaro Estrada, Secretarin de Relaciones Exteriores, quien había traído de España cinco poemas inéditos de García Lorca para que se publicaran en la primera revista. Al respecto Octavio Paz refiere:

"El primer número fue, en gran parte, ideado, realizado y pagado por Solana. En el sumario, además de los poemas, ensayos y comentarios de los 'responsables', figuraban colaboraciones notables: unos poemas inéditos de García Lorca, rescatados por Genaro Estrada, con ilustraciones de Moreno Villa, notas de Villaurrutia y Revueltas [...]" 
Esos poemas se encuentran entre las páginas 33 y 50 . La primera de ellas presenta un dibujo de la cara de García Lorca, realizado por José Moreno Villa en diciembre de 1937, seguido de la siguiente explicación sobre su inclusión:

"Todos estos poemas de Federico García Lorca fueron copiados por Genaro Estrada, en una de sus pequeñas libretas negras, y traídos a México como inéditos. El 'Pequeño vals vienés', que se publicó aquí en una revista, había aparecido ya, en vida de Federico, en el cuaderno número uno de la serie '1616' English and Spanish Poetry, que en 1934 Manuel Altolaguirre editó en Londres. Hemos preferido esta versión publicada con conocimiento de García Lorca, a la que apareció en México. En todo lo demás nos hemos atenido al original en poder de Estrada, copiado e interpretado en las palabras que ofrecían duda por José Moreno Villa".

El primer poema que aparece, inmediatamente después del texto anterior, es "Pequeño vals vienés". En efecto, según consta en las obras completas, publicadas por Aguilar, en la vigésimosegunda edición de 1986, en la nota del recopilador Arturo del Hoyo, este poema no estuvo incluido en algún libro de poesía de García Lorca; sino publicado en el cuaderno de la serie "1616", en Londres, en 1934. Este poema fue escrito el 13 de febrero de 1930, según consta al final de él en la revista Taller. Cito un fraginento del mismo.

En Viena hay diez muchachos, un hombro donde llora la muerte y un bosque de palomas disecadas.

En Viena hay una calle que desemboca en el aire.

Hay un fragmento de la mañana en el museo de la escarcha.

Hay un salón con mil ventanas ¡Ay!, ¡ay!, ¡ay!, ¡ay!

¡Toma este vals con la boca cerrada!

Este vals, este vals, este vals

de sí, de nieve y de coñac que moja su cola en el mar.

Excepto el poema anterior, los restantes cuatro realmente estuvieron inéditos hasta su publicación en Taller.

El segundo poema es "La suite del agua" y consta de nueve partes tituladas, País, Temblor, Acacia, Curva, Colmena, Norte, Sur, Este, Oeste. Tiene una ilustración de Moreno Villa donde se figura, desdibujadamente, una sombra que baila abrazada a otra; la primera simula la muerte por medio de una silueta cuya 
calavera escurre agua o llora y un pie sólo con huesos; ella baila o abraza a otro ser sin rostro, mejor dicho, sin cabeza, y cuyo cuerpo, que apenas se dibuja (o desdibuja) parece el de un hombre. A lo lejos, y en la parte de enmedio hacia la derecha se observa una media luna; asimismo se añaden cuatro líneas curvas que semejan nubes o gotas o palabras o astros, las cuales se encuentran arriba de la parte posterior de la calavera danzante y dolorosa.

La ilustración se relaciona con el poema completo que, en sus nueve partes, refleja sensaciones de depresión, insatisfacción, muerte con un lenguaje surrealista muy sugerente. Veamos tres de ellos:

\section{País}

En el agua negra

árboles yacentes

margaritas

y amapolas.

Por el camino muerto

van tres bueyes

Por el aire,

el ruiseñor

corazón del árbol.

Acacia

¿Quién segó el tallo

de la luna?

(Nos dejó raíces

de agua)

¿Qué fácil nos sería cortar las flores

de la eterna acacia!

Norte

Las estrellas frías

sobre los caminos. 
Hay quien va y quien viene

por selvas de humo

Las cabañas suspiran

bajo la aurora perpetua.

En el golpe

de hacha

valles y bosques tienen

un temblor de cisterna.

¡En el golpe

del hacha!

Las imágenes sorprendentes del agua negra, los árboles yacentes, el camino muerto, el corazón del árbol y el tallo de la luna segado y sus raíces de agua, las flores cortadas, las estrellas frías, los seres que van y vienen por las selvas de humo, el temblor de la cisterna, el golpe del hacha, todas estas imágenes mágicas pueden tener un hilo conductor de insatisfacción o de muerte.

En el tomo 1 de la obras completas de García Lorca, anteriormente citado, en la p. 1159 en la nota al poema anterior se expresa lo siguiente:

"Suite del agua._Publicada por Genaro Estrada en Taller, México, núm.1, diciembre de 1938; incorporado por Guillermo de Torre a las obras completas de F.G.L. (Losada); compuesta a comienzos de 1921, según Belamich en su citada edición."

Andrés Belamich es un traductor al francés de la obra de García Lorca, quien publicó sus obras completas en París, en 1981, e incluyó estos poemas, así como la nota de su publicación primera en Taller.

El tercer poema, "Cuatro baladas amarillas", está formado por cuatro partes y se somete, en cuanto a su forma poética, a su poesía tradicional, al cantarcillo popular con lenguaje surrealista. Antes de finalizar el poema tiene otra ilustración de Moreno Villa. En ésta se dibuja al poeta sentado, con la mano derecha en la barbilla, sosteniendo su cara, de la cual solo se observan las cejas muy negras y sus ojos cerrados. Podemos percibir una sensación de soledad en la figura, pero también una presencia etérea, porque lo escoltan tres estrellas alineadas entre cuatro números: dos romanos, el XII y el III y dos arábigos, el 1 y el 2.

Veamos la primera balada y la cuarta:

III

En lo alto de aquel monte hay un arbolito verde. 
Pastor que vas, pastor que vienes.

Olivares soñolientos bajan al llano caliente.

Pastor que vas pastor que vienes,

Ni ovejas blancas, ni perro, ni cayado, ni amor tienes.

Pastor que vas

Como una sombra de oro en el trigal te disuelves.

Pastor que vienes.

\section{IV}

Sobre el cielo

de las margaritas ando.

Yo imagino esta tarde que soy santo.

Me pusieron la luna en las manos; yo la puse otra vez en el espacio y el ruiseñor me premió con la rosa y el halo.[...]

Sobre el cielo de las margaritas ando.

La nota correspondiente a las obras completas de Aguilar expresa lo siguiente:

"Suite escrita antes del 2 de agosto de 1921, citada por el autor en carta a Adolfo Salazar de esa fecha. Hay manuscrito autógrafo, reproducido en 
facsímil en El pez y la serpiente, Managua, núm. 2, agosto de 1961, [siendo que Taller la publicó en el '39] con dedicatoria a Pedro Garfias".

Como puede observarse, este poema también era inédito y su primera publicación se realizó en la revista Taller. El compilador Arturo del Hoyo no se dio a la tarea de revisar nuestra revista para obtener la información más actualizada.

El cuarto poema, "La selva de los relojes", presenta un poema introductorio, sin nombre, y siete poemas más con los siguientes títulos: Maleza, Vista general, Él, Donde se ahoga el sueño, Eco del reloj, Meditación primera y última y La hora esfinge. El hilo conductor de estos poemas es la presencia constante y preocupante del tiempo de la vida personal, tiempo que tiene ya limitado su horizonte, el de la muerte, expresado a través del eco del reloj, de la meditación de la hora final cuando las lunas blancas se hundirán por los montes o cuando "la hora fría" ponga su techo de piedra a las mariposas líricas y corte y limite sus alas para siempre.

Frondas de tic-tac, racimos de campanas

y, bajo la hora múltiple, constelaciones de péndulos.

Los lirios negros

de las horas muertas, los lirios negros de las horas niñas ¡Todo igual! ¿Y el oro del amor?

Hay una hora tan solo. ¡Una hora tan solo! ¡La hora fría!

"La hora esfinge" UNA...dos... y tres. sonó la hora en la selva. Se llenó de burbujas y un péndulo de oro llevaba y traía mi cara por el aire. ¡Sonó la hora en la selva! 
Los relojes del bolsillo, como bandadas de moscas iban y venían.

En la nota correspondiente a las ya citadas Obras completas se expresa lo siguiente:

"Publicada por Genaro Estrado en Taller, México, diciembre, 1938; incorporado por Guillermo de Torre a las O.C. de F.G.L. [Losada]; su fecha posible, según Belamich (Op. cit.): noviembre 1922."

El último de los poemas es "Herbarios" y contiene tres poemas que refieren tres herbarios: el primero es un herbario de olor y color y lo lleva un viajante de jardines quien:

“[...] abre el libro llorando

y los colores errabundos

se desmayan sobre el herbario"

El segundo es un herbario de sueños y lo lleva un viajante del tiempo. Refle$\mathrm{ja}$, al igual que el anterior y el posterior, el punto final de la vida, el camino, también mágico hacia la hora final. Es un diálogo entre el poeta y el viajante. El poeta pregunta ¿cuántos siglos han pasado? El viajante contesta: Una sola hora tiene mi herbario. El poeta pregunta ¿voy al alba o a la tarde?, y el viajante afirma: El pasado está inhabitable. El poeta exclama: ¡Oh, jardín de la amarga fruta! El viajante concluye: Peor es el herbario de la luna.

El último es un herbario de los ruidos:

En mucho secreto, un amigo

me enseña el herbario de los ruidos.

(¿Chist... silencio!

La noche cuelga del cielo)

A la luz de un puerto perdido

vienen los ecos de todos los siglos.

(¿Chist... silencio!

La noche oscila en el viento)

Chist... silencio!

Viejas iras se enroscan en mis dedos. 
La nota correspondiente en las Obras completas multicitadas también da el crédito de su primera publicación a Genaro Estrada y a la revista Taller y anota como fecha de su escritura diciembre de 1922, tomada también de la propia revista que la tiene anotada al calce.

Ésta ha sido la presencia de García Lorca en Taller, en diciembre de 1938, dos años después de su muerte.

Sólo me resta añadir que la presencia del poeta español y el influjo que de él recibieron los miembros de esta generación no se queda sólo en estas páginas que hemos revisado, sino que hubo una continuidad: bebieron de la poesía de García Lorca de donde extrajeron no sólo la belleza de la imagen poética heredada del surrealismo, sino también la nueva fuerza de la palabra popular y la necesidad de cultivar los géneros tradicionales con formas y ritmos en consonancia con el lenguaje y la vida de nuestras ciudades; asimismo, la decisión de explorar ese inmenso territorio que es el alma popular. Sin duda, en el diálogo que se estableció entre España e Hispanoamérica, estaba la palabra poética de García Lorca.

Al revisar la presencia de García Lorca en la obra de Octavio Paz, encontré no menos de un centenar de citas que hacían referencia, entre muchas otras cosas, al ritmo y musicalidad de su poesía, a la manera como el teatro recupera su voluntad poética en manos de García Lorca, a la fuerza de su poesía tradicional que lo convierte en uno de los poetas más leídos del mundo, cuyos poemas se encuentran entre los más intensos de la literatura universal; su paso del neobarroquismo gongorino al surrealismo; su gusto por el uso del metro corto por ser el mejor modelo de concentración verbal; su capacidad de unir la tradición española con la vanguardia poética; su dominio notable de la poesía, poderosa detonación de explosivas imágenes de una ciudad más soñada que vista en su libro Poeta en Nueva York, que nos expresan más de la vida íntima y voluntad creadora de Lorca que de Nueva York; el por qué el genio de Lorca le hace pensar en la música, sobre todo la de Bartok; como en él la muerte es un centro magnético indistinguible de la pasión sexual, pero no es obsesivo; al fervor con que fueron leídos por el grupo de Taller los poetas, prosistas y ensayistas del 98 y del 27 y la forma como los influyó la literatura española moderna; cómo asoció el surrealismo al andalucismo en sus primeros poemas.

En una revisión del influjo de Lorca en los poetas de esta generación encontramos su presencia constante, la lucha por devolverle a la palabra su fuerza, su belleza, el sentido de ser y hacer del hombre. Esta generación se identifica con García Lorca en que todos tocaron el mundo a través de la poesía, del amor y la muerte y entendieron y vivieron la palabra poética como una apasionada, heroica disolución del hombre en el mundo. 